\title{
Properties and Characteristics of Compressed Biofuel Production from Empty Palm Fruit Bunches
}

\author{
Tanuwat Larptansuphaphol ${ }^{*}$ and Penja Jitjumroonchokchai \\ Department of Biotechnology, Faculty of Applied Science, King Mongkut's University of Technology North Bangkok, Thailand.
}

\begin{abstract}
Thailand sits in the third place of the global rankings for crude palm oil production with an annual output of approximately 2 million tons/p.a., or $1.2 \%$ of the global output. Empty palm fruit bunches is one of residual from palm oil extraction process of Palm Oil industry. The objective of this research was to study properties and characteristics of biofuel made from empty fruit bunches and mixed with black rice hush with various composition ratios of empty palm fruit bunches and black rice husk as 100:0, 90:10, 80:20, 70:30, 60:40 and 50:50. Only the biofuels with a ratio of 100:0 and 90:10 could be formed to be compressed biofuels. The heating values of biofuels were analyzed by Gallenkamp Autobomb Calorimeter whereas other fuel properties and characteristics were tested and analyzed according to ASTM standards. The comparison results between biofuel from a mixture ratio 100:0 and 90:10 showed that the average of heating value, ash content, carbon content and combustion time (minute per one piece) were 4,672.46 and 4,199.33 cal/g, $21.73 \%$ and $29.30 \%$, $12.07 \%$ and $16.28 \%, 92.33$ and 63 minutes, respectively.
\end{abstract}

\section{Introduction}

The Oil Palm plant (Elais Guinensis) produces a fruit with a nut inside the fruit. The fruit is boiled in water to extract the palm oil. After the oil extraction from the fruit, the nuts are broken for the palm kernels. The broken shells are called palm kernel shell. In the palm oil processing operations, the solid wastes are: empty fruit bunches, palm fibre, and palm kernel shell. In rural community levels, palm kernel shells are used in their crude form for heating during cooking. However it burns with a lot of smoke due to its organic content. The effect of such smoke to health cannot be over emphasized. Even in such cases most of the energy content is not used up as palm kernel shell charcoals which are common sight at ash dumps [1].

Palm empty fruit bunches is waste residue generated from palm oil industries. After harvesting fresh fruit bunches from oil palm tree, these bunches are sterilized in a horizontal steam sterilizer to inactivate enzymes present in pericarp and loosen fruits from bunches. The sterilized bunches are fed into a rotary drum thresher in order to remove the sterilized fruit from bunches.

These bunches without fruit are called as empty fruit bunch which are conveyed to the damping ground, whereas the sterilized fruits are further used as feedstock for palm oil production in palm oil extraction process by means of screw type press. The effluents from screw type press are nuts and fibers which are separated from each other by cyclone. After this separation, nuts are cracked into shells and kernels [2].

The palm oil plants are found in most parts, especially, southern states of Thailand. The different parts of the oil palm are adapted for different useful purposes. While the leaves provide brooms for tidying the environment, the kernel is a major source of red palm oil used for cooking. The Palm empty fruit bunches were converted into briquettes by adopting very simple process, utilizing readily available and affordable materials [3]. The briquettes produced from Palm empty fruit bunches were tested for their combustion and physical characteristics. Summers studied about using rice straw for energy production and told that rice straw has a higher value about $16,000 \mathrm{MJ} / \mathrm{Kg}$ and meaning a potential fuel base of $1.8 \times 1010 \mathrm{MJ}$ in the rice growing region of California [4]. Chou et al. investigated the feasibility of preparing the biomass briquettes by the solid waste, such as rice straw and rice barn [5]. Biomass pellets are generally a superior fuel when compared to their raw feedstock. Not only are the pellets more energy dense, they are also easier to handle and use in automated feed systems. These advantages, when combined with the sustainable and ecologically sound properties of the fuel [6]. Global waste biomass energy capacity is about eight times the annual world consumption of energy from all sources. Therefore biomass represents a very large energy resource, in Eastern Europe was used biomass energy in industrial more than 10 years and this low

Corresponding author: tanuwat.1@sci.kmutnb.ac.th 
burning rate restricts the use of these biomass energy to small capacity applications such as stoves and domestic heating furnaces $[7,8]$.

This project of bio-fuel made from Palm empty fruit bunches aimed to reduce greenhouse gases such as carbon dioxide (CO2) from biomass waste in open burning areas. The objective was to make bio- fuels as a renewable energy source. Utilization wastes from palm oil industry were cover processing of bio-fuels, costs and environmental benefits.

\section{Material and Methods}

Palm empty fruit bunches were collected from Thai Oil Industry Co., Ltd. at Samutsakorn province. Black rice husk was added in a ratio of palm empty fruit bunches: black rice husk (by weight) as 100:0: , 90:10, 80:20, $70: 30,60: 40$ and 50:50 respectively. Bio-fuel was compressed by using screw machine to form a $6 \mathrm{~cm}$. diameter and $10 \mathrm{~cm}$. height cylinder shape fuel. Palm empty fruit bunches as shown below in Figure 1.

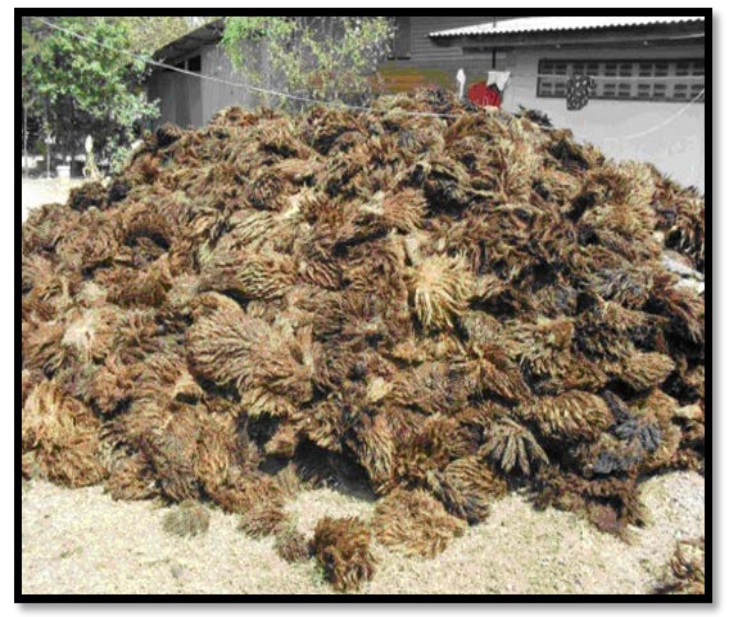

Fig. 1 Dried palm empty fruit bunches

Properties and characteristics of compressed bio-fuel made from palm empty fruit bunches were tested and analyzed as follows: moisture content, volatile components, ash, carbon, hydrogen, oxygen, nitrogen and sulfur under ASTM (American Testing Standard Materials) D3173, D3174 and D4239. Gross calorific value was measured by using Gallenkamp Autobomb Calorimeter Instrument according to ASTM D5685. Experimental data were analyzed by analysis of variance (ANOVA) and Duncan's New Multiple Range (DMRT) at significant $5 \%$. The schematic diagram of statistical analysis as shown below:

$\mathrm{T}=$ Ratio of empty fruit bunches: black rice husk

$\mathrm{T} 1=100: 0, \mathrm{~T} 2=90: 10, \mathrm{~T} 3=80: 20, \mathrm{~T} 4=70: 30, \mathrm{~T} 5=$

$60: 40$ and $\mathrm{T} 6=50: 50$

$\mathrm{R}=$ sample
$\mathrm{R} 1=$ sample1, R2 =sample3 and R3 = sample3

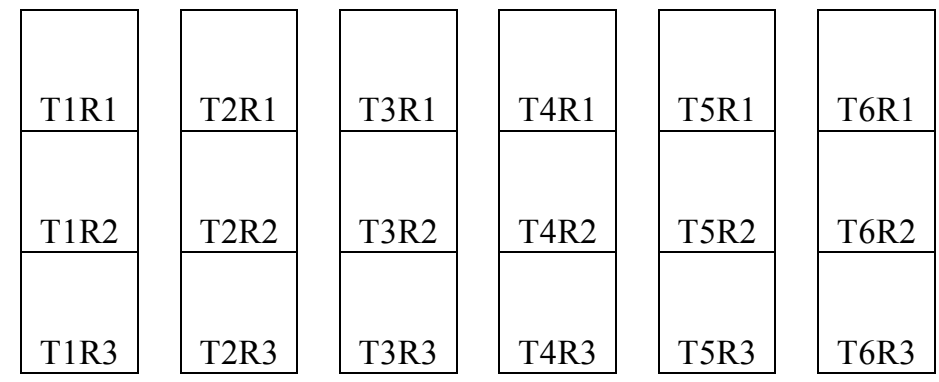

\section{Results and Discussion}

\subsection{Physical characteristics}

General physical characteristics of compressed fuel made from Palm empty fruit bunches that were taken from Thai Oil Industry Co., Ltd. at Samutsakorn province were tested at KMUTNB laboratory. The physical biomass fuels were shown in Figure 2. The physical and chemical characteristics of compressed bio-fuel made from Palm empty fruit bunches were shown in table 1.

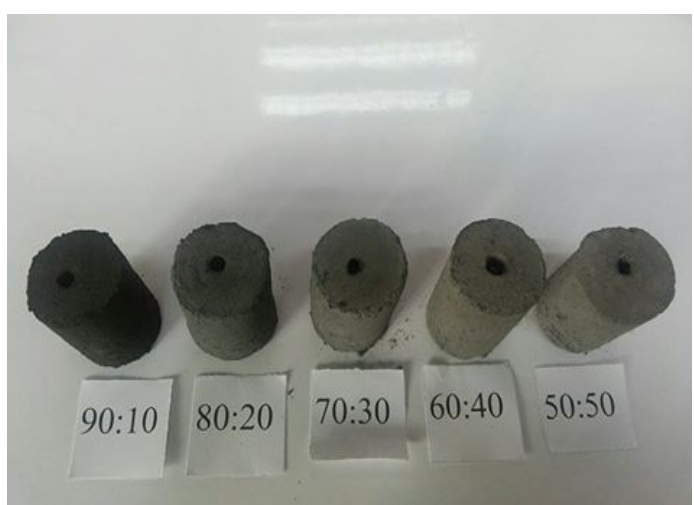

Fig 2. Physical characteristics of compressed bio-fuel made from Palm empty fruit bunches

Table 1 Physical characteristics of compressed fuel made from Palm empty fruit bunches

\begin{tabular}{|c|c|}
\hline Characteristics & $\begin{array}{c}\text { \% by weight of Palm empty fruit } \\
\text { bunches } \\
\text { (one piece) }\end{array}$ \\
\hline $\begin{array}{c}\text { Moisture } \\
\text { content (\%) }\end{array}$ & 18.22 \\
\hline Ash (\%) & 6.55 \\
\hline $\begin{array}{c}\text { Fixed carbon } \\
(\%)\end{array}$ & 38.10 \\
\hline $\begin{array}{c}\text { Bulk Density, } \\
\mathrm{kg} / \mathrm{m}^{3}\end{array}$ & 288.05 \\
\hline
\end{tabular}




\subsection{Physical and chemical properties of compressed bio-fuel}

After compressed bio-fuel was dried in an open area for 7 days, all samples of 6 ratios of Palm empty fruit bunches: black rice husk were tested and analyzed in a laboratory. The samples were tested and analyzed for their physical and chemical properties of biomass energy according to ASTM standard methods. The results of testing and analysis of compressed bio-fuel made from palm empty fruit bunches: black rick husk were shown in Table 2 .

Table 2 Physical and chemical properties of compressed biofuel at various ratios

\begin{tabular}{|c|c|c|c|c|c|c|}
\hline $\begin{array}{c}\text { Physical/Chemical } \\
\text { properties }\end{array}$ & $100: 0$ & $90: 10$ & $80: 20$ & $70: 30$ & $60: 40$ & $50: 50$ \\
\hline $\begin{array}{c}\text { Moisture content } \\
(\%)\end{array}$ & 17 & 20 & 18 & 17 & 21 & 16 \\
\hline $\begin{array}{c}\text { Volatile matters } \\
(\%)\end{array}$ & 87 & 86 & 88 & 85 & 84 & 83 \\
\hline Ash content (\%) & 13 & 17 & 19 & 20 & 20 & 16 \\
\hline Fixed carbon (\%) & 30 & 33 & 35 & 34 & 35 & 37 \\
\hline Hydrogen (\%) & 4.1 & 4.8 & 4.8 & 4.9 & 4.0 & 3.9 \\
\hline Oxygen (\%) & 41 & 44 & 46 & 40 & 42 & 45 \\
\hline Nitrogen (\%) & 0.55 & 0.48 & 0.53 & 0.49 & 0.39 & 0.33 \\
\hline Sulphur (\%) & 0.19 & 0.17 & 0.18 & 0.21 & 0.23 & 0.18 \\
\hline
\end{tabular}

Table 2 showed the results of proximate analysis (volatile matters, fixed carbon and ash content) calculating on a dry and ash-free basis. The ultimate analysis was analyzed for all elements such as carbon(C), hydrogen $(\mathrm{H})$, Nitrogen $(\mathrm{N})$, Oxygen $(\mathrm{O})$ and Sulphur(S) by using Gas Chromatography technique. The results indicated that ratio of palm kernel shell: black rice husk as 50:50 had the lowest moisture content $16 \%$.

European Biomass Association suggested that a moisture content of raw materials to be a compressed fuel should be $12-17 \%$ and it was not exceed these values [9]. In addition, compressed fuel should be stored in a closed system or a room, a silo, bunkers, plastics and air light zip bags (dry conditions) and storage times should be minimized to prevent absorption from atmospheric moisture. However, the bulk material supply was necessary and available in all seasons [10].

\subsection{Heating value}

Higher heating value was experimentally determined in a bomb calorimeter by concealing a stoichiometric mixture of fuel and oxidizer (e.g., two moles of hydrogen and one mole of oxygen) in a steel container at $25^{\circ} \mathrm{C}$. Fuel sample was initiated by an ignition device and the combustion reactions completed. When hydrogen and oxygen reacted during combustion, water vapor emerged. Subsequently, a vessel and its content were cooled down to an original temperature $25^{\circ} \mathrm{C}$ and the higher heating value was determined as the heat released between identical initial and final temperatures [11] .

The CV (Calorific Value) of a substance was measured by burning it in a controlled environment. The result of heat released by this combustion i.e. the net temperature rise, was proportional to the calorific value. In an adiabatic system the environment was controlled so that no energy lost or gained. In order to achieve this state, a Calorimeter Vessel (bomb) and a bucket were surrounded by a water jacket which was strictly temperature controlled by a system of circulators, heaters and coolers, so that it had the same temperature as an inner bucket. The Isothermal calorimeter measured an effect that the environment had on the bucket before and after determination and correction of the results accordingly. This implied that the environment was stable during the determination. In order to achieve a stability condition, a large body of water surrounding the vessel and bucket assembly was thermally stable [12].

Heat of combustion was transferred to cooling water around Bomb calorimeter. Water temperature was measured by thermometer. Amount of heat transfer was calculated by equation (1).

$$
\mathrm{Q}=\mathrm{mc}\left(\mathrm{T}_{1}-\mathrm{T}_{2}\right)
$$

where

$$
\begin{aligned}
& \mathrm{Q}=\text { fuel combustion heat } \\
& \mathrm{m}=\text { mass of water in Calorimeter } \\
& \mathrm{c}=\text { specific heat of water } \\
& \mathrm{T}_{1}=\text { water temperature before } \\
& \text { combustion } \\
& \mathrm{T}_{2}=\text { water temperature after } \\
& \text { combustion }
\end{aligned}
$$

Fuel thermal energy could be determined from equation (2).

$$
\mathrm{HHV}=\frac{(\Delta T \cdot w)-e}{g}
$$

where

$$
\begin{aligned}
& \mathrm{HHV}=\text { Combustion heat } \\
& \Delta T \quad=\text { heat increasing } \\
& \text { temperature }\left({ }^{\circ} \mathrm{C}\right) \\
& \mathrm{W} \quad=1,724.187\left(\mathrm{cal} /{ }^{\circ} \mathrm{C}\right) \\
& \mathrm{e} \quad=\text { combustion heat correction } \\
& \text { factor }=2.3(\mathrm{cal} / \mathrm{cm}) \times \text { combustion } \\
& \text { wire length }(\mathrm{cm}) \\
& \mathrm{g} \quad=\text { fuel sample weight }(\mathrm{g})
\end{aligned}
$$




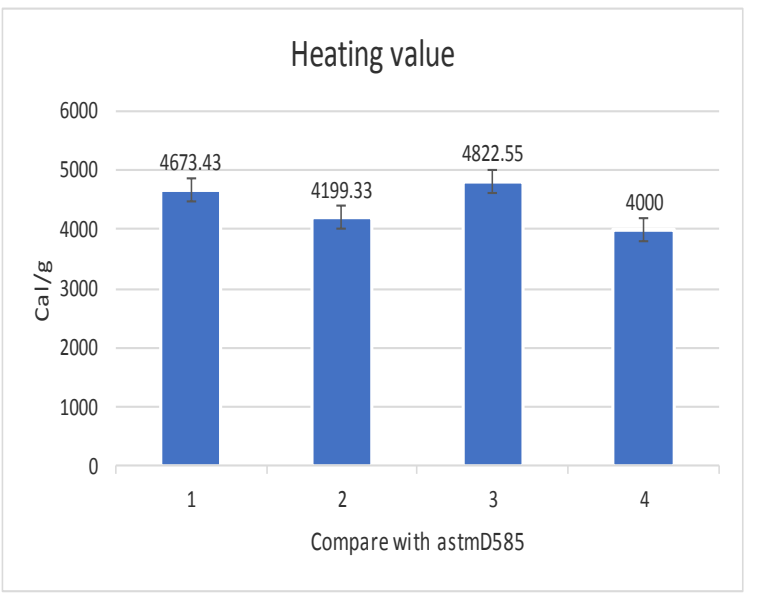

1/ Palm empty fruit bunches $100 \%$

2/ Palm empty fruit bunches : black rice husk 90:10

3/ Wood compressed bio-fuel

4/ Standard ASTM D5865

Fig. 3 Comparison of heating value of various fuels with ASTM D5865

Figure 3 showed the comparison results of heating values of various samples with standard ASTM D5865. The results indicated that the heating value by Bomb Calorimeter was about 4,672.43 cal/g and 4,199.33 cal/g from the ratio of Palm empty fruit bunches: black rice husk at 100:0 and 90:10 respectively.

\subsection{Determination of heat utilization efficiency}

Thermal behavior of compressed bio-fuel had been studied by measuring the rate of weight loss of the samples as a function of time and temperature. Thermal combustion energy could be measured by the time from initial to final until water was boiled at its boiling point. The maximum average time for heat utilization efficiency was about 92.33 minutes from the ratio of Palm empty fruit bunches $100 \%$ no addition of black rice husk.

Various ratios of combiner mixtures were analyzed for the best combination of mixtures. The ratio of Palm empty fruit bunches: black rice husk palm as 90:10 was the best combiner. The highest temperature of this compressed fuel at 63 minutes of combustion time at 99.31 o C. Percentage of ash from combustion in 60 minutes.

Ash content was determined by percentage of compressed fuel combustion depending on the time of experiment in 60 minutes. The lowest ash content was the result at ratio of Palm empty fruit bunches: black rice husk as 90:10. From the results showed that ash contents of 6 ratios of samples after 60 minute that 5 ratios of samples mixed with binder had higher ash content compared with compressed wood fuel. Ash content in compressed wood fuel was usually less than $1 \%$, while it could be very high in many agricultural residues. That was why compressed wood fuel quality standards could not be reached when using agricultural residues as feedstock and another, specified quality standard for agricultural compressed fuel needed to be introduced [13].

\section{Conclusion}

The advantages of compressed fuel production are as follows: alternative energy for people both in the urban and rural areas, wastes reduction by agricultural wastes reuse and recycle, renewable energy from living organisms, alternative fuel market for low cost. Moreover, compressed fuel made from Palm empty fruit bunches can be developed for export to increase national incomes.

The rise in energy costs as interlinked of food prices. The residues from agriculture area used to be renewable energy is the way to help people in developing country to use cheap energy and reduce growing plants for energy. That means food and energy security is the safety way of human being in the future.

The percentage of ash content measured from Biofuel still higher than wood (1-2\% of ash). In addition, ash content can originate from the biomass itself or from binder and often lead to high disposal costs resulting in a negative economic impact on biomass conversion systems. Ash content values may vary significantly from one biomass resource to another. In this energy conversion processes it is not only the amount of ash, but also its physical and chemical properties that should be considered.

Finally, the government should start looking into providing the necessary infrastructure, technology and expertise for the use of potential power supply from oil mills and other biomasses (like solid wastes).

Furthermore, the private sector such as SMEs should be a partner with the government for funding and investment for energy stability in the country.

The author would like to thank for Department of Mechanical Engineering, Faculty of Engineering, King Mongkut's University of Technology, North Bangkok for analytical support of heating values by Bomb Calorimeter Instrument.

\section{References}

1. UGWU,KE;AGBO, KE.Briquetting of Palm Kernel Shell. J. Appl. Sci. Environ. Manage. Sept, Vol. 15 (3) 447 - 450(2011). 
2. Abd, Halm Shamsuddin. Palm Oil Products and Wastes as Alternative Energy Sources. PERIC International Energy Journal: Vol 11, No.2, Dec. 1989.

3. Obuka Nnaemeka, Onyechi Pius, Okoli Ndubuisi. Palm Oil Biomass Waste a Renewable Energy Resource for Power Generation Saudi J. Eng. Technol., Vol 3, Iss-12 (Dec, 2018): 680-691.

4. Matthew D. Summers .Using Rice Straw for Energy Production: Economics, energetics and Emissions. http://jenkins.ucdavis.edu/projects/RiceStra w/RiceStrawDocs/SummersEBS216FinalRe port.pdf(2010).

5. C.S Chou, S.H. Lin, W.C. Lu, Preparation of solid biomass fuel made from rice straw and rice bran, Fuel Processing Technology (9), pp. 980-987. DOI :10.1016/j/fuproc_2009.04.012. (2009).

6. Manufacturing Fuel Pellets from Biomass. www.pubs.cas.psu.edu/Free Pubs/pdf/uc202 pdf.(2010)

7. Berger H. Zimmer H J and Garmo J. Ontersuchngen zur charakateristerung von strohpellets G. verdaulich- keitsuntersuchungen an weizenstrohpellets. Archiv. Tiermahr. 24, pp. 689700. (1984)

8. Ewida K.T., H EL-Salmawy, N.N. Atta and M.M. Mahmoud . A sustainable approach to the recycling of rice straw through pelletization and controlled burning. Clean Tech environ Policy Journal, 8, pp. 188-197. DOI 10.1007/s10098-006-0043-x. (2011)

9. European Biomass Association (2000). http://www.energyagency.at/(en)/publ.(2010).

10. Bergram PCA, Kiel J. A. . Torre faction for biomass upgrading published at 14th European Biomass Conference and Exhibition, Paris, France, 17-21 ECNRX-05-180, 2005-12-18.(2005).

11. http://en.wikipedia.org/wiki/Heat_of_comb ustion (2011).

12. http://www.cal2k.com/article_10.asp(2013).

13. Significant biomass properties. Part 2: Ash content. http://www.biomassenergy.gr/en/articles/bi omass/315-significant-properties-part-2ash-content(2014). 